\title{
A Postharvest Fruit Rot of Apple Caused by Lambertella corni-maris in Washington State
}

M. S. Wiseman, Department of Plant Pathology, Washington State University, Pullman; F. M. Dugan, United States Department of Agriculture-Agricultural Research Service (USDA-ARS), Pullman, WA; Y. K. Kim, Pace International, Wapato, WA; and C. L. Xiao, USDA-ARS, San Joaquin Valley Agricultural Sciences Center, Parlier, CA 93648

\begin{abstract}
Wiseman, M. S., Dugan, F. M., Kim, Y. K., and Xiao, C. L. 2015. A postharvest fruit rot of apple caused by Lambertella corni-maris in Washington State. Plant Dis. 99:201-206.

During surveys for postharvest diseases of apple conducted in Washington State, an unknown fruit rot was observed on stored apple fruit collected from commercial fruit packinghouses. This disease was present in 66 of the 179 grower lots sampled, accounting for an average 1 to $3 \%$ of the total decayed fruit sampled. The disease appeared to originate from infection of wounds on the fruit skin. Lesions were brown and decayed tissues were spongy. A Lambertella sp. was consistently isolated from the decayed fruit. Sequences of the fungus and those of Lambertella corni-maris in GenBank differed by 0 to 4 bp across the combined small ribosomal subunit + internal transcribed spacer + large ribosomal subunit regions with a maximum identity ranging from 99 to $100 \%$. The fungus grew at 0 to $20^{\circ} \mathrm{C}$ and formed apothecia on artificial media after 8 to 24 weeks. On potato dextrose agar under a 12-h

$\mathrm{mm}$ in diameter with stipes of 1 to 4 by $0.5 \mathrm{~mm}$. Asci were 76 to 125 by 3.5 to $5.5 \mu \mathrm{m}$, inoperculate, eight-spored, clavate, and narrowed at the base. Ascospores were aseptate, 7 to 10 by 2.5 to $4.5 \mu \mathrm{m}$, uniseriate to biseriate, and orange-brown at maturity in the ascus. Colony characteristics included little or no aerial mycelium, dark-yellow to grayblack mycelium, gray-black pseudosclerotia, and yellow pigmentation in the agar. Morphological characteristics of the fungus overlapped with the description of L. corni-maris. 'Fuji' apple fruit that were wounded, inoculated with representative isolates, and incubated at $0^{\circ} \mathrm{C}$ yielded the same symptoms as seen in packinghouses, and the fungus was reisolated from the diseased fruit. This is the first report of a fruit rot in stored apple caused by L. corni-maris in the United States. We propose Lambertella rot as the name of this disease.
\end{abstract} photoperiod, apothecial dimensions were variable, ranging from 1 to 6
Washington States produces over 50\% of the fresh apple fruit in the United States, with a 2011 value of $\$ 1.83$ billion (17). At harvest, apple fruit are placed in wooden or plastic bins and then transported to cold-storage and packing facilities. Although harvested apple fruit no longer have access to nutrients and water, the fruit still continue to metabolize stored substances, consume $\mathrm{O}_{2}$, and release $\mathrm{CO}_{2}$ during respiration to create metabolic energy needed to sustain various anabolic and catabolic processes (10). To delay natural senescence to prolong storage life, apple fruit are often stored in regular atmosphere or in controlled atmosphere (1 to $2 \% \mathrm{O}_{2}$ and $0.5 \% \mathrm{CO}_{2}$ ) at -1 to $4{ }^{\circ} \mathrm{C}(12)$. Because a large volume of fruit needs to be packed and marketed, fruit may be stored for up to 12 months. Postharvest diseases caused by various fungal pathogens can be a limiting factor for the long-term storage of fruit. In Washington State, apple fruit are commonly drenched prior to storage with a fungicide alone or in combination with diphenylamine (an antioxidant) for control of postharvest fruit rots and superficial scald (browning of apple fruit skin) (32). Despite technological advances in postharvest handling of fresh fruit, post-

\section{Corresponding author: C. L.Xiao, E-mail: Chang-Lin.Xiao@ars.usda.gov}

Disclaimer: Mention of trade names or commercial products in this article is solely for the purpose of providing specific information and does not imply recommendations or endorsement by the United States Department of Agriculture (USDA). USDA is an equal opportunity provider and employer.

* The $\boldsymbol{e}$-Xtra logo stands for "electronic extra" and indicates that a supplementary table is available online.

Accepted for publication 28 August 2014.

http://dx.doi.org/10.1094/PDIS-03-14-0327-RE

This article is in the public domain and not copyrightable. It may be freely reprinted with customary crediting of the source. The American Phytopathological Society, 2015. harvest fruit losses range from 5 to $20 \%$, with upward of $50 \%$ in underdeveloped countries (7).

There are over 90 fungi reported to be associated with postharvest fruit rots of apple (5). Postharvest fruit rot diseases fall into three major groups: those that originate from latent fungal infections of fruit in the field, those that originate from infections during postharvest processing and transport, or those that originate from infections during storage $(22,31)$. Neofabraea perennans, causal agent of bull's-eye rot, exemplifies a pathogen that infects apple fruit in the orchard and remains latent before harvest, leading to decay after an extended period of storage (23). Penicillium expansum infects apple fruit during harvest and postharvest handling via wounds present in apple fruit (21), whereas Botrytis cinerea exemplifies a pathogen that can cause fruit rots by mycelial spread fruit to fruit during storage (30).

During surveys for postharvest diseases of apple conducted in Washington State from 2003 to 2005, decayed apple fruit were sampled from six commercial packinghouses in central Washington State (8), and an unknown fruit rot disease was observed on stored apple fruit collected from fruit packinghouses. The disease appeared to originate from infections of wounds on the fruit. Lesions were brown and decayed tissues were spongy. A dark yellow fungus was consistently isolated from the decayed fruit exhibiting these symptoms. The objectives of this study were to (i) describe symptoms and occurrence of this disease, (ii) identify the causal agent using morphological and molecular phylogenetic approaches, and (iii) test pathogenicity of the fungus on apple fruit.

\section{Materials and Methods}

Symptoms and incidence of the disease in storage. The unknown disease we reported here was observed during surveys of postharvest diseases on apple fruit conducted during apple storage from June to August 2003 and from March to August 2004 and 2005 , and the details of the surveys have been previously described (8). Briefly, decayed apple fruit were sampled from six commercial packinghouses, representing orchards in various apple-producing 
areas in Central Washington State. In this study, each grower lot represents one orchard. In all, 26 grower lots of 'Red Delicious' were collected from June to August 2003; and 72 grower lots (39 Red Delicious, 19 'Golden Delicious', and 14 'Fuji') and 81 grower lots (37 Red Delicious, 19 Golden Delicious, and 25 Fuji) were collected from March to August 2004 and 2005, respectively. Symptoms and infection sites on decayed fruit were recorded, and isolations of fungi associated with the decayed fruit were attempted (8).

Fungal isolates. Eleven isolates of the dark yellow fungus were used throughout this study. These isolates were recovered from decayed apple fruit collected from commercial fruit packinghouses during postharvest disease surveys in Washington State during 2003 to 2005, as described previously (8). Because apothecia formation for the fungus was inconsistent among isolates, hyphal tip isolation was used to obtain isogenetic cultures for each isolate for the majority of experiments. Initially, a small agar block (approximately $1 \mathrm{~mm}$ in diameter) from actively growing 7- to 10-day-old potato dextrose agar (PDA; Difco Laboratories, Detroit) cultures were transferred onto a new PDA plate and allowed to incubate at room temperature for 48 to $72 \mathrm{~h}$. Hyphal tips were aseptically removed from each of these plates and transferred to fresh PDA. Finally, another hyphal tip transfer was made from the previous plate 48 to $72 \mathrm{~h}$ later. Isolates derived from hyphal tip isolation were stored as mycelial plugs in liquid nitrogen vapor.

After apothecial formation and maturation, ascospores were also used to obtain single-spore cultures for some isolates. Mature apothecia discharged ascospores that often stuck to the lid of the petri plates. Spores on the petri plate lids were scraped off into a small droplet of sterile water. This spore suspension was streaked onto PDA and grown out for $48 \mathrm{~h}$ at room temperature in a 12-h photoperiod with a mixed spectrum of near-ultraviolet (NUV) and cool white fluorescent light. Single-spore colonies were transferred to PDA and stored in liquid nitrogen vapor.

Morphology and culture studies. Morphological characteristics. Isolates CLX2872 and CLX3892 were used for morphological observations. Isolates were grown on PDA at $21^{\circ} \mathrm{C}$ in a 12 -h photoperiod with a mixed spectrum of NUV and cool white fluorescent light. Observations of apothecia, ascospores, and asci were executed upon maturation of apothecia (approximately 2 to 6 months), as determined by earliest detection of ascospore discharge. In all, 25 measurements were conducted for apothecial dimensions and 50 measurements for both asci and ascospores under $\times 1,000$ magnification using an Olympus $\mathrm{BH} 2$ microscope. Then, a 95\% confidence interval was calculated using these data (Microsoft Excel 2008, Seattle).

Temperature studies. Isolates CLX2872 and CLX3892 were evaluated for mycelial growth on PDA at different temperatures. Two replicates, each with three plates for each isolate, were seeded with mycelial plugs (approximately $4 \mathrm{~mm}$ in diameter) cut from the margins of 10-day-old cultures on PDA. Inoculated plates were then sealed with Parafilm, wrapped in foil, and incubated in darkness at $0,20,30$, or $37^{\circ} \mathrm{C}$. Colony diameter on each plate was measured using electronic calipers at $7,9,14$, and 28 days. This experiment was conducted twice.

Germination of ascospores. Ascospores from a mature apothecium of isolate CLX2872 were scraped onto a sterile glass slide with a small amount of sterile water. A sterile cover slip was then placed over the ascospores and the slide was placed into a petri dish sealed with Parafilm and stored at room temperature (approximately $21^{\circ} \mathrm{C}$ ) for a 12 -h photoperiod with a mixed spectrum of cool white fluorescent and NUV light. Germination of ascospores was examined every $12 \mathrm{~h}$.

Molecular phylogenetic analysis. Production of mycelia and extraction of DNA. Hyphal-tipped isolates were grown in deep-dish yeast extract broth plates (yeast extract broth; Difco Laboratories) at $20^{\circ} \mathrm{C}$ under a $12-\mathrm{h}$ photoperiod with a mixed spectrum of cool white fluorescent and NUV light. After 3 weeks, the mycelium was harvested, rinsed three times with sterile deionized $\mathrm{H}_{2} \mathrm{O}$, centrifuged into a pellet, and placed in a $-80^{\circ} \mathrm{C}$ freezer for a minimum of $24 \mathrm{~h}$. Prior to DNA extraction, the mycelium was removed from the $-80^{\circ} \mathrm{C}$ freezer and lyophilized for $48 \mathrm{~h}$. Genomic DNA was extracted from the lyophilized culture using FastDNA SPIN Kit and the FastPrep Instrument following the manufacturer's instructions (MP Biomedicals, Santa Ana, CA). DNA was visualized under UV light in $0.8 \%$ agarose gels containing ethidium bromide at $0.5 \mu \mathrm{g} / \mathrm{ml}$. Genomic DNA was diluted by $\times 10$ with sterile $\mathrm{ddH}_{2} \mathrm{O}$ and stored at $-20^{\circ} \mathrm{C}$.

Polymerase chain reaction amplification conditions and phylogenetic analyses. The nuclear internal transcribed spacer (ITS) region ribosomal DNA, including ITS1, 5.8S, and ITS2 regions, was amplified using the primers ITS5 (5'GGAAGTAAA AGTCGTAACAAGG3') and ITS4 (5'TCCTCCGCTTATTGA TATGC3') (28). The small ribosomal subunit (SSU) region was amplified using the primers NS1 (5'GTAGTCATATGCTTG TCTC3') and NS4 (5' CTTCCGTCAATTCCTTTAAG3') (28). The large ribosomal subunit (LSU) region was amplified using primers LR0R (5'ACCCGCTGAACTTAAGC3') and LR5 (5'TCCTGA GGGAAACTTCG3') (25). Polymerase chain reaction (PCR) was conducted with a final volume of $20 \mu$ l containing $14 \mu \mathrm{l}$ of PCR Taq master mix (Qiagen Inc., Valencia, CA), $3 \mu$ of sterile $\mathrm{ddH}_{2} \mathrm{O}$, $1 \mu \mathrm{l}$ of 10-ng genomic DNA, and $1 \mu \mathrm{l}$ of each primer. PCR amplification was done using the Applied Biosystems Veriti Thermal Cycler under the conditions described in the source literature $(25,28)$. Amplicons were visualized under UV light in $1 \%$ agarose gels containing ethidium bromide at $0.5 \mu \mathrm{g} / \mathrm{ml}$, and PCR products were purified with QIAquick PCR purification columns (Qiagen Inc.), then Sanger sequenced bidirectionally (Eurofins MWG Operon, Huntsville, AL) using the primers above and internal primers ITS2 for the ITS region, LR16 and LR3R for the LSU region, and NS3 for the SSU region $(1,13,28)$. Sequences were edited using Sequencher version 5.1 sequence analysis software (Gene Codes Corporation, Ann Arbor, MI) and aligned using Clustal Omega (EMBL-EBI) and Mesquite version 2.75 (11). Sequences were deposited into GenBank under the accession numbers found in Table 1.

Bayesian phylogenetic analysis was done using Mr. Bayes v.3.0b4 (6). Additional taxa used for the phylogenetic analyses were obtained from GenBank and chosen based on a reputable expert identification and high percent identity match (>85\%) (Supplementary Table S1). The best-fit model of sequence evolution for the dataset was selected and model parameter estimates obtained using jModelTest 2.1.3. The SYM+I+G model was selected by jModelTest as the best-fit model of evolution for these data and was implemented in the Bayesian analysis (19). Posterior probabilities were determined by generating phylogenetic trees from 200,000 Markov Chain Monte Carlo (MCMC) chains with a 0.1 burn-in fraction sampling done every 1,000 MCMC chains. Phylograms were edited using FigTree v 1.4.0 (20).

Pathogenicity tests. To test pathogenicity of the fungus on apple, organically grown Fuji apple fruit (Malus domestica) were obtained at harvest from Tonnemaker Farms, Royal City, WA. Fruit were washed with liquid dish soap, gently rubbed, rinsed in sterile water, surface disinfested in a $0.8 \% \mathrm{NaClO}$ solution for $2 \mathrm{~min}$, and independently rinsed two more times with sterile water. All fruit were stored at approximately $4^{\circ} \mathrm{C}$ prior to inoculation.

Surface-disinfested fruit were inoculated with mycelium of isolates CLX2872 or CLX3892 grown for 7 to 10 days on PDA plates under a 12-h photoperiod with a mixed spectrum of NUV and cool white fluorescent light. For the controls, PDA was transferred into the wound site $(0.25 \mathrm{~mm}$ in depth, $1 \mathrm{~mm}$ in diameter). Wounds were made using a uniform wounding tool. Fruit were incubated in individual plastic containers and placed in a larger container with a water reservoir separate from the fruit to keep high relative humidity. The larger containers were sealed with plastic wrap, taped, and placed into the same 0 to $2^{\circ} \mathrm{C}$ cold room. Both of the isolate treatments and their controls were randomized within the larger containers. Conditions were monitored with a HOBO data logger (Onset Computer Corporation, Bourne, MA). After 6 weeks, fruit were examined for decay development at the inoculation site, and 
lesion sizes on decayed fruit were measured using electronic calipers. Identical incubation procedures were followed for another experiment using an ascospore suspension at $5 \times 10^{5}$ ascospores $/ \mathrm{ml}$ of liquid $\mathrm{H}_{2} \mathrm{O}$ agar as inoculum to test pathogenicity via spore inoculation. Ascospore suspensions were made by rinsing ascospores off petri dish lids (of mature cultures) and then adjusting the concentration of spores in the liquid agar using a hemacytometer.

If a fruit had a lesion surrounding the inoculation site, reisolation of the causal agent was attempted. Fruit were sprayed twice with $70 \%$ ethanol, allowed to dry in a biological safety cabinet, and then rinsed with sterile deionized water. Tissues from the margin of the lesions were aseptically excised and transferred to PDA or acidified PDA (4 ml of $25 \%$ lactic acid solution per 1 liter of PDA). Morphology of the fungus was assessed at 4 to 7 days and mycelium of selected isolates was harvested for sequencing of the ITS region. Fruit with lesions were stored for varying amount of times ( 2 to 6 months) at 0 to $2^{\circ} \mathrm{C}$ and then exposed to room temperature for 4 to 6 months under a 12-h photoperiod in attempts to simulate vernalization and induce apothecial production.

\section{Results}

Symptoms, prevalence, and incidence of the disease. Symptoms of decayed fruit associated with this unknown disease collected from commercial fruit packinghouses were apparently rots from infections of wounds on the fruit skin; lesions were brown and decayed tissues were spongy (Fig. 1A and B). The decayed fruit flesh also was brown (not shown). Under high relative humidity, white or white to gray mycelium may form on the decayed area (Fig. 1C). A fungus was consistently isolated from decayed fruit with symptoms as described above. On PDA, the fungus produced little or no aerial mycelium, dark-yellow to gray-black mycelium, and yellow pigmentation in the agar. On 7- to 10-day-old PDA cultures, the fungus secreted yellow-orange crystals on the medium. The fungus formed gray-black pseudosclerotia as it aged.

This unknown disease associated with the dark-yellow fungus occurred in 5 of 26 grower lots (19\%), accounting for 1.9 to $6 \%$ of the decayed fruit in the infected lots, with an average $1 \%$ of the total decayed fruit sampled in 2003; 28 of 72 grower lots (39\%), accounting for 1.8 to $42 \%$ of the decayed fruit in the infected lots, with an average $1.9 \%$ of the total decayed fruit sampled in 2004; and 33 of 81 grower lots (41\%), accounting for 1.8 to $45 \%$ of the decayed fruit in the infected lots, with an average $2.7 \%$ of the total decayed fruit sampled in 2005.

Molecular phylogenetic analysis. The results of the phylogenetic analysis revealed a well-supported clade of Lambertella corni-maris and the unknown fungus (Fig. 2). The final phylogenetic tree consisted of $596 \mathrm{bp}$ from the ITS region and part of the LSU region. Three haplotypes were present among the eight isolates in the concatenated SSU+ITS+LSU regions, differing by 1 to
3 bp (haplotypes indicated in Table 1). Sequences of the unknown fungus and deposited L. corni-maris sequences differed by 0 to 4 bp across the combined SSU+ITS+LSU regions, with a maximum identity of 99 to $100 \%$. The specific haplotype CLX3871 represented the largest difference in maximum identity from $L$. cornimaris sequences deposited in GenBank, differing by 4 bp with $L$. corni-maris isolate FC-2389 (GenBank accession numbers AB705239.1 and AB705279.1).

Taxonomy. On the basis of the presented morphological and molecular data, the fungus was identified as Lambertella cornimaris Höhn.

Lambertella corni-maris Höhn., Sber. Akad. Wiss. Wien, Math.-naturw. Kl., Abt. 1 127: 375 (1918). Apothecial diameter highly variable in culture (diameter: 1 to $6 \mathrm{~mm}$ ) depending on nutrient availability and light; apothecia cup-shaped to flat, stipitate; produced from substratal stroma; color of apothecia changes with age but often starting yellowish-beige turning to brown-black. Excipulum concolorous to darker, glabrous. Stipe 1 to $4 \mathrm{~mm}$ long by $0.5 \mathrm{~mm}$ wide. Asci inoperculate, eight-spored, 76 to $125 \times 3.5$ to $5.5 \mu \mathrm{m}$; clavate, narrowing at the base. Ascospores 7 to $10 \times 2.5$ to $4.5 \mu \mathrm{m}$, biguttulate, usually obliquely uniseriate sometimes biseriate; ascospores hyaline then transitioning to orange-brown to brown within the ascus; predominately subfusoid to ellipsoid; occasionally banded. Spermatia formed from flask-shaped fasciculate spermatiophores in sporodochia growing superficially on the stroma; smooth, ellipsoid to globose, hyaline when viewed individually or olivaceous in mass. Subhymenium pigmented or not, of interwoven to parallel and vertically oriented hyphae. Inner ectal excipulum composed of darkly pigmented textura prismatica; hairs absent; ectal excipulum darkly pigmented textura porrecta (Fig. 3).

Specimens examined. United States, Washington State: Mattawa, Grant County, on a decayed fruit of 'Fuji' apple (Malus domestica), 12 Apr 2004, C.L. Xiao 2872 (WSP 72433; 72435), a piece of dried apple bearing pseudosclerotia and a dried culture bearing apothecia is included; Mattawa, Grant County, on a decayed fruit of 'Fuji' apple (Malus domestica), 28 Mar 2005, C.L. Xiao 3862 (WSP 72436) a dried culture bearing apothecia is included; Tricities, Benton County, on a decayed fruit of 'Fuji' apple (Malus domestica), 23 Mar 2004, C.L. Xiao 3852 (WSP 72434) a dried culture bearing apothecia is included; Chelan, Chelan County, on a decayed fruit of 'Red Spur Stripe' apple (Malus domestica), 12 May 2004, C.L. Xiao 3042 (WSP 72437) a dried culture bearing apothecia is included.

Growth responses to temperature. Radial growth of the two isolates increased from 0 to $20^{\circ} \mathrm{C}$. Growth ceased at temperatures $\geq 30^{\circ} \mathrm{C}$. The average radial growth for CLX2872 was $0.53( \pm 0.26)$ and $2.91( \pm 0.13) \mathrm{mm} /$ day at 0 and $20^{\circ} \mathrm{C}$, respectively. The average radial growth for CLX3892 was $1.01( \pm 0.05)$ and $3.77( \pm 0.24)$ $\mathrm{mm} /$ day at 0 and $20^{\circ} \mathrm{C}$, respectively. The agar plugs from plates

Table 1. Details of Lambertella corni-maris isolates, origins, and GenBank accession numbers

\begin{tabular}{|c|c|c|c|c|c|c|}
\hline \multirow[b]{2}{*}{ Culture number ${ }^{z}$} & \multirow[b]{2}{*}{ Collection date } & \multirow[b]{2}{*}{ Geographic locale } & \multirow[b]{2}{*}{ Host cultivar } & \multicolumn{3}{|c|}{ GenBank accession number ${ }^{y}$} \\
\hline & & & & ITS & LSU & SSU \\
\hline CLX2872 a* & 12 April 2004 & Mattawa, WA & Fuji & KC958553 & КС964849 & KC964859 \\
\hline CLX2872R a & 15 December 2012 & $\ldots$ & Fuji & KC958554 & KC964850 & КC964860 \\
\hline CLX3042 a & 12 May 2004 & Chelan, WA & Red Delicious & KC958555 & KC964851 & KC964861 \\
\hline CLX3852 & 23 March 2004 & Pasco, WA & Fuji & $\ldots$ & $\ldots$ & $\ldots$ \\
\hline CLX3853 a & 23 March 2004 & Pasco, WA & Fuji & KC958556 & KC964852 & KC964862 \\
\hline CLX3862 b & 28 March 2005 & Mattawa, WA & Fuji & KC958557 & КC964853 & КC964863 \\
\hline CLX3867 & 24 March 2005 & Malaga, WA & Fuji & $\ldots$ & $\ldots$ & $\ldots$ \\
\hline CLX3871 c* & 28 March 2005 & Mattawa, WA & Fuji & KC958558 & KC964854 & КC964864 \\
\hline CLX3872 a & 28 March 2005 & Mattawa, WA & Fuji & КC958559 & KC964855 & KC964865 \\
\hline CLX3892 a* & 28 March 2005 & Tri-cities, WA & Fuji & КС958560 & КС964856 & КС964866 \\
\hline CLX4050 a & 20 April 2005 & Chelan, WA & Fuji & КC958561 & KC964857 & КC964867 \\
\hline CLX4075 a & 20 April 2005 & Chelan, WA & Red Delicious & KC958562 & КС964858 & КС964868 \\
\hline
\end{tabular}

\footnotetext{
y ITS = internal transcribed spacer, LSU = large ribosomal subunit, and SSU = small ribosomal subunit.
}

${ }^{\mathrm{z}}$ All isolates are maintained at the Washington State University Tree Fruit Research and Extension Center, Wenatchee and at Washington State University, Pullman. Each different letter following the culture number represents a specific isolate haplotype among the concatenated SSU+ITS+LSU regions. In addition to hyphal tipping, isolates marked with an asterisk (*) were also subjected to single-spore isolations 
that exhibited no growth at $30^{\circ} \mathrm{C}$ were transferred into new PDA plates and incubated at room temperature $\left(21\right.$ to $\left.22^{\circ} \mathrm{C}\right)$ for 14 days. Isolate CLX3892 resumed growth once exposed to room temperature but isolate CLX2872 did not. Germination of viable ascospores occurred within 48 to $72 \mathrm{~h}$ in deionized $\mathrm{H}_{2} \mathrm{O}$ at $20^{\circ} \mathrm{C}$.

Pathogenicity on apple fruit. Lesions appeared on inoculated apple fruit within 6 weeks of incubation and were light brown. As the fungus colonized the apple fruit, thick, yellow-tan, felt-like mycelia emerged and formed pseudosclerotia on the surface of the fruit (Fig. 1). Infection of apple fruit was also successful with the spore inoculation. In 12 weeks, $>80 \%$ of the inoculated apple fruit developed the decay symptoms. Isolations from lesions on the fruit consistently yielded a fungus displaying growth and morphological characteristics identical to those previously described. ITS sequencing of the isolates recovered from decayed fruit inoculated with the fungus confirmed the identity of the causal agent. Several attempts to initiate sexual production were made by altering lighting or temperature conditions for fully colonized fruit but no sexual stage was ever observed.

\section{Discussion}

This is the first report of a fruit rot in stored apple fruit caused by L. corni-maris. Previously, in 1935, Harrison and El-Helaly (4) reported $L$. corni-maris associated with mummified apple and pear fruit on the orchard floor in abandoned orchards in Switzerland and Germany, respectively; furthermore, they discovered that, in the laboratory tests, L. corni-maris has the ability to infect a variety of fruit and vegetables, including members of the Rosaceae family: apple, pear, quince, and plum (4). However, they did not report whether they observed the disease on apple fruit on the trees in the orchard or on stored apple fruit after harvest, and the pathogenicity tests by Harrison and El-Helaly were conducted at $20^{\circ} \mathrm{C}$. In the present study, we observed $L$. corni-maris associated with a fruit rot disease on apple fruit in commercial cold storage and documented that isolates of $L$. corni-maris from decayed apple fruit are able to grow at $0^{\circ} \mathrm{C}$ and have the ability to cause rots on apple fruit stored at cold temperatures that are commonly used commercially for storage of apple fruit, indicating that the fungus is a postharvest pathogen on apple. We propose Lambertella rot as the name of this postharvest disease in apple.
L. pruni has been reported to occur on fruit and seedlings of Prunus spp. in the western United States (3). To address the $L$. pruni isolates that fell into the L. corni-maris clade, morphological comparisons were made utilizing existing literature. Dumont's (2) comprehensive key on Lambertella spp. was utilized to identify the fungus based on morphological characteristics. Working in the order of Dumont's dichotomous key (2), our fungus was identified as L. corni-maris because asci are eight-spored with regularly maturing ascospores, the pore of the ascus is $\mathrm{J}+$ (turns blue in iodine), hairs are absent on the excipulum, ascospores are biguttulate, fusiod to elliposoid, not pseudostriate, one type of interthecial element is present, and ascospores are typically uniserate and pigmented and lack punctations (2). Focusing on the differences between our fungus and L. pruni, isolate CLX2872's ascospores are subfusoid to ellipsoid, as compared with $L$. pruni's lunateshaped ascospores (2). Furthermore, L. pruni has substantially larger asci (122 to 137 by 11 to $13 \mu \mathrm{m}$ versus 80 to 135 by 7 to 8 $\mu \mathrm{m})$ and ascospore dimensions ( 15 to 18 by 7 to $8 \mu \mathrm{m}$ versus 7 to 12 by 4 to $7 \mu \mathrm{m}$ ), as compared with L. corni-maris (2). L. pruni's placement in the L. corni-maris clade could be a result of misidentification of the voucher for the putatitve $L$. pruni but, in any case, $L$. pruni is unambiguously morphologically distinct from the description for L. corni-maris and from our specimens. L. cornimaris has several closely related species based on morphological features. L. corni-maris's thick-walled, sometimes banded ascospores distinguish it from closely related species $L$. agaricicola, $L$. aurantiaca, $L$. bonahawensis, $L$. garryae, L. himalayensis, and $L$. jasmini $(2,9)$. Ascospore dimensions further differentiate $L$. cornimaris from similar species in the genus (L. fructicola and L. acuminata) $(2,27)$.

Morphological and molecular data from this study strongly support the conclusion that the unknown fungus is $L$. corni-maris. $L$. corni-maris was first discovered in Austria by von Höhnel, in 1917, on Cornus mas L. mummified fruit. Subsequently, L. cornimaris was described and proposed as the generic type by von Höhnel (26). Comparing morphological features of our fungus with the type description strongly suggests that the fungus in question is conspecific with that of von Höhnel, because their ascus, ascospore, apothecium, and spermatium dimensions; cultural characteristics; and growth patterns all overlap $(2,4,26,27)$. Other spe-
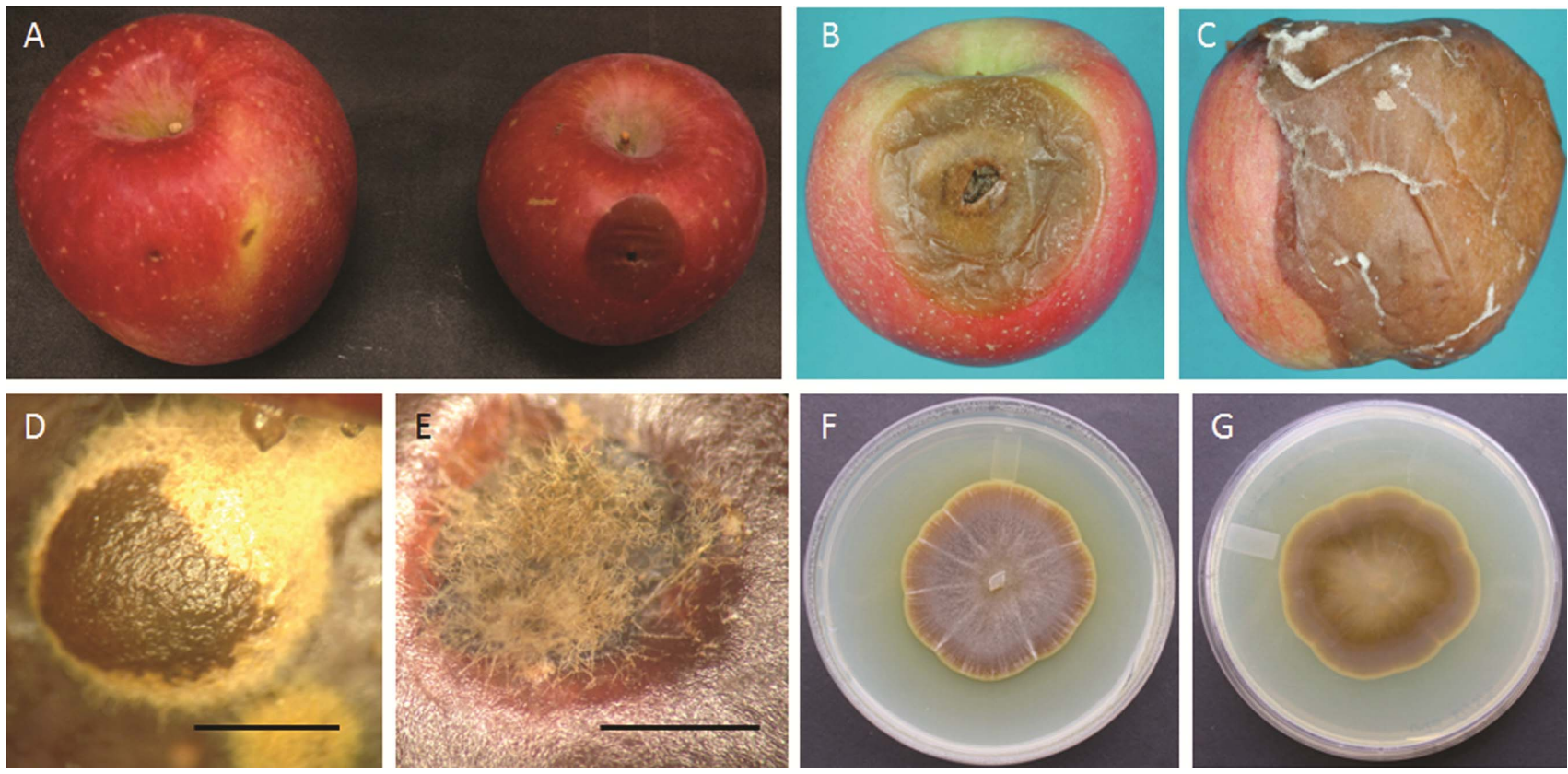

Fig. 1. Symptoms of a fruit rot caused by Lambertella corni-maris on apple fruit and appearance of the fungus in culture; A, Decay caused by a Lambertella corni-maris wound infection from the laboratory pathogenicity test: control on the left, inoculated apple with isolate CLX2872 on the right; B and C, Symptoms from wound infections on 'Fuji' apple fruit recovered from a commercial fruit packinghouse; $\mathbf{C}$, advanced decay; $\mathbf{D}$ and $\mathbf{E}$, $\times 50$ view of pseudosclerotial formation on the apple surface; $\mathbf{F}$ and $\mathbf{G}$, 7-dayold reisolation from decayed apple fruit on potato dextrose agar culture grown at $20^{\circ} \mathrm{C}$ under a 12 -h photoperiod showing yellow growth margins darkening to gray-black toward the inoculation point; reverse of the plate, showing yellowing of agar seen surrounding the fungus's actively growing margin. Scale bars: $\mathrm{D}$ and $\mathrm{E}=1 \mathrm{~mm}$. 


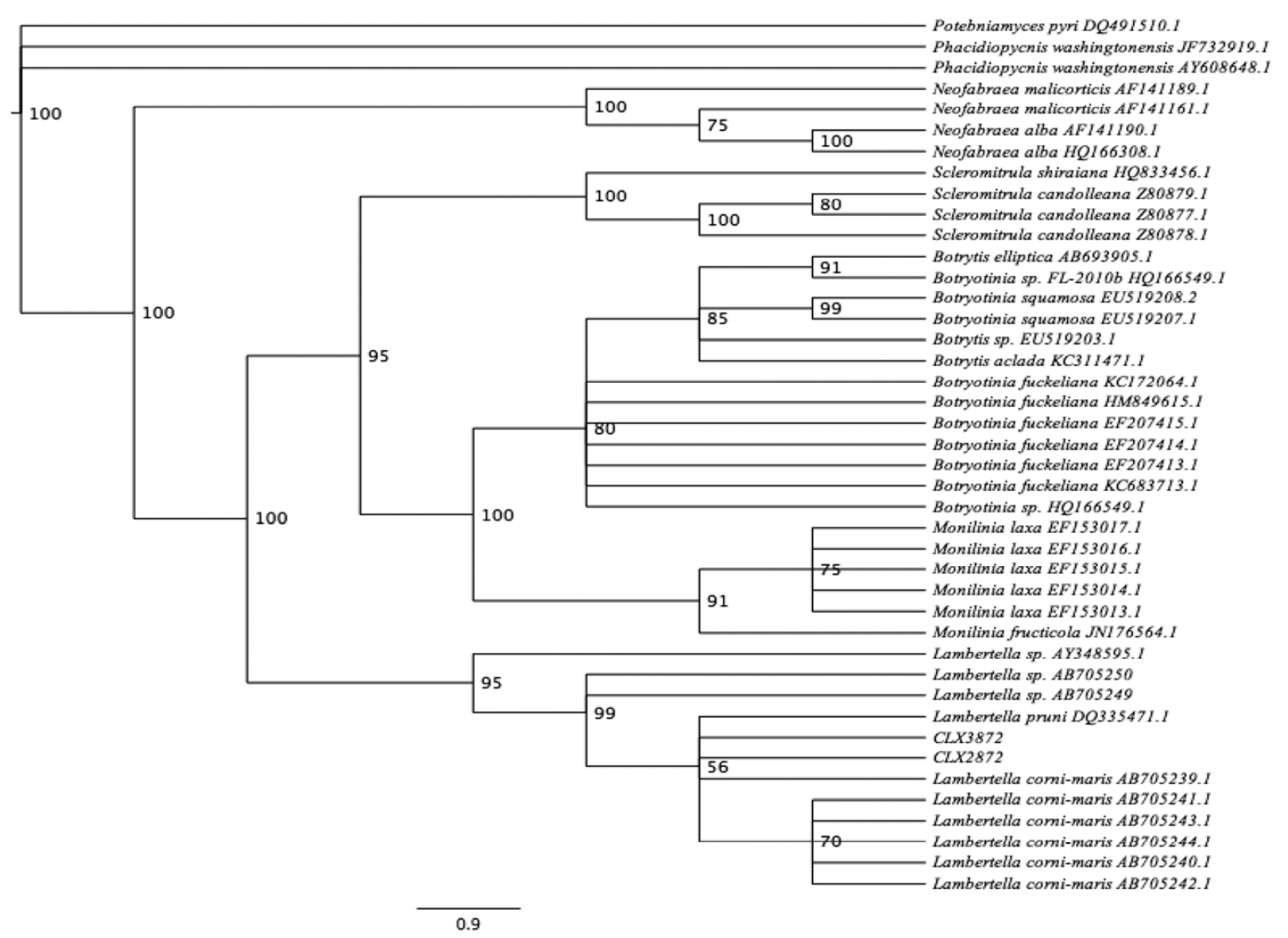

Fig. 2. Molecular phylogenetic analysis of the internal transcribed spacer (ITS)1,5.8S ribosomal RNA (rRNA), ITS2, and partial 28S rRNA sequences by Bayesian methods. The user-specified tree topology was analyzed by using the Bayesian methods based on the SYM+1+G model as determined by jModelTest. Numbers represent Bayesian posterior probabilities that were sampled from 402 trees generated from 200,000 Markov Chain Monte Carlo chains. Representative isolates CLX2872 and CLX3872 consistently grouped into the Lambertella corni-maris clade. The tree was rooted using the Phacidiopycnis and Potebniamyces spp. clade as an outgroup.
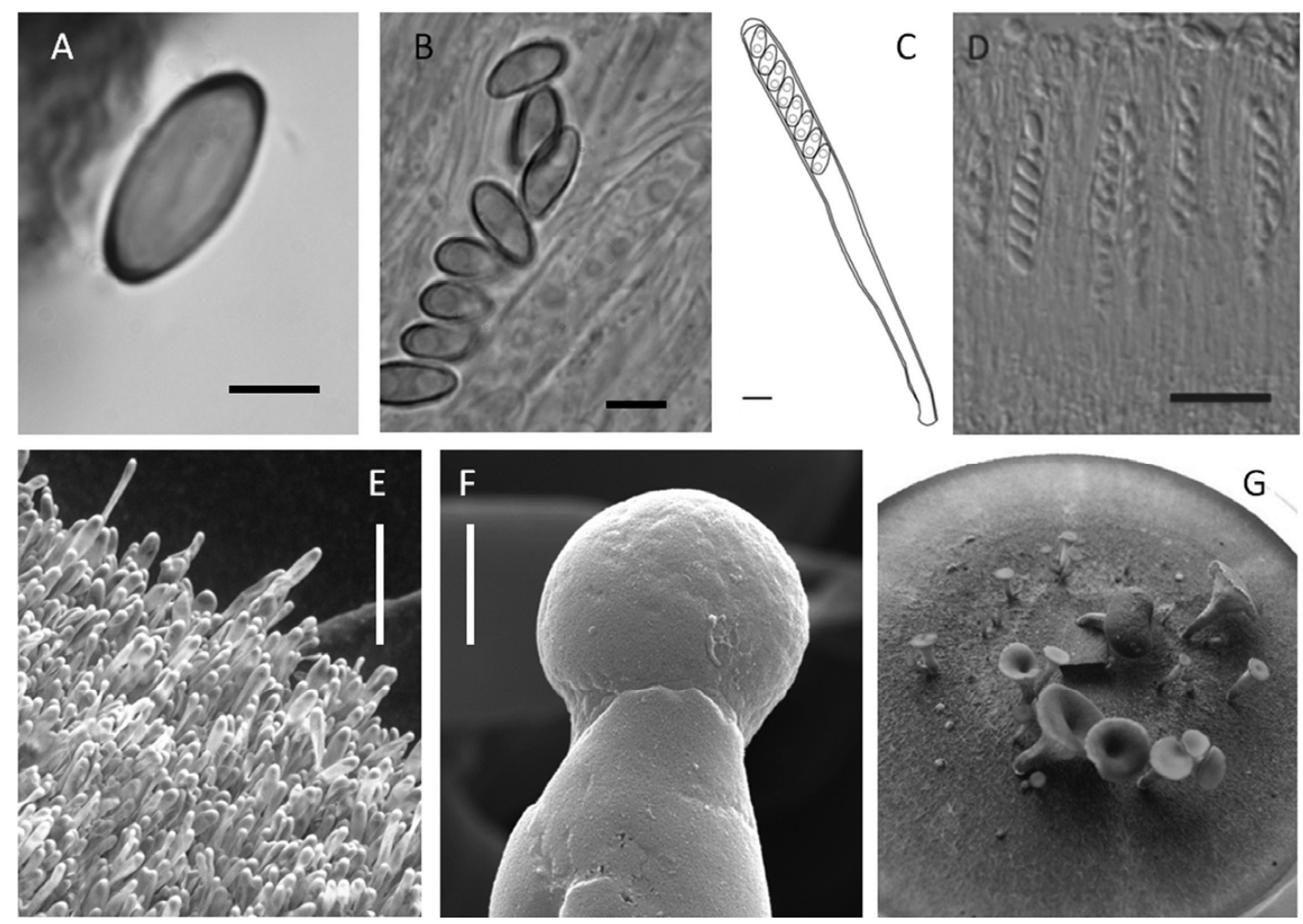

Fig. 3. Lambertella corni-maris micrographs and illustrations. A, Ascospore from CLX2872; B, mature ascus with ascospores on the left and immature ascus with developing hyaline ascospores on the right; $\mathbf{C}$, camera lucida drawing of a mature ascus and ascospores; $\mathbf{D}$, immature asci viewed with differential interference contrast (DIC); $\mathbf{E}$, hymenium of apothecium as viewed with scanning electron microscopy (SEM); $F$, spermatium formation (SEM); $\mathbf{G}$, apothecia in various growth stages on oat agar in a 90-mm culture dish. Scale bars: $A, 5 \mu \mathrm{m} ; \mathrm{B}$ and $\mathrm{C}, 10 \mu \mathrm{m} ; \mathrm{D}, 25 \mu \mathrm{m} ; \mathrm{E}, 25 \mu \mathrm{m} ; \mathrm{F}, 12 \mu \mathrm{m}$. 
cies in the genus similar to our fungus, such as $L$. jasmini and $L$. hicorae, are differentiated from our fungus by differences in coloration of apothecial stipes, colony growth characteristics, and documented host range (27). Previous work has examined the crystal secretions and found mycoparasitic properties in the genus Lambertella (4,14-16,29). In 1951, Wood (29) discovered L. cornimaris's antagonistic properties against fungi and bacteria such as B. cinerea, Staphylococcus aureus, and Mycobacterium phlei. Later, it was discovered that Lambertella spp. were antagonistic against a variety of other fungi, such as Monilinia fructigena, because of their antibiotic and antifungal properties $(16,24)$.

As mentioned previously, L. corni-maris often secretes yelloworange crystals after 7 to 10 days on PDA at room temperature. These orange crystals are found in a variety of Lambertella spp. and were discovered to be antibiotics (lambertellols A and B and lambertellin) which were produced in high quantities under acidic conditions (16). Nomiya et al. (18) further investigated the antibiotics and concluded that L. corni-maris secretes lambertellols A and B which are then transformed into lambertellin to inhibit $M$. fructigena. A high-performance liquid chromatography analysis would need to verify the identity of the orange crystals of our fungus.

How long this fungus and disease have been present in the region is unknown. The survey for postharvest diseases of apple conducted during 2003 to 2005 indicated a low incidence of this disease in stored apple fruit under commercial storage conditions. However, this disease accounted for up to 30 to $45 \%$ of the total decayed fruit in a few grower lots among the lots sampled in 2004 and 2005, indicating that the disease may have the potential to cause a notable level of losses. Our observations indicated that this disease on apple fruit caused by the dark-yellow fungus was associated with infections of wounds, such as stem punctures and bruises, on the fruit. Thus, minimizing wounds on the fruit by careful handling would reduce the incidence of this disease. Currently registered postharvest fungicides fludioxonil, pyrimethanil, and thiabendazole are highly effective in controlling this disease when they are used as postharvest drench treatments (C. L. Xiao, unpublished data). It is likely that the disease, if present, is under control with the current postharvest handling practices.

\section{Acknowledgments}

We thank R. J. Boal and S. Lupien for technical assistance and G. Grove, W. Chen, and J. Rogers for helpful suggestions for the research.

\section{Literature Cited}

1. De Hoog, S., Zalar, P., Van Den Ende, B. G., and Gunde-Cimerman, N. 2005. Relation of halotolerance to human-pathogenicity in the fungal tree of life: An overview of ecology and evolution under stress. Springer. http://link.springer.com/chapter/10.1007/1-4020-3633-7_25

2. Dumont, K. P. 1971. Sclerotiniaceae II. Lambertella. Mem. New York Bot. Gard. 22 (1):1-178

3. Farr, D. F., Bills, G. F., Chamuris, G. P., and Rossman, A. Y. 1989. Fungi on Plants and Plant Products in the United States. American Phytopathological Society, St. Paul, MN.

4. Harrison, T. H., and El-Helaly, A. F. 1935. On Lambertella corni-maris von Höhnel, a brown-spored parasitic discomycete. Trans. Br. Mycol. Soc. 19:199-214.

5. Heald, F. D., and Ruehle, G. D. 1931. The rots of Washington apples in cold storage. Ext. Bull. No. 253, State College of Washington, Pullman.

6. Huelsenbeck, J. P., Ronquist, F., Nielsen, R., and Bollback, J. P. 2001. Bayesian inference of phylogeny and its impact on evolutionary biology. Science 294:2310-2314.

7. Janisiewicz, W. J., and Korsten, L. 2002. Biological control of postharvest diseases of fruits. Annu. Rev. Phytopathol. 40:411-441.

8. Kim, Y. K., and Xiao, C. L. 2008. Distribution and incidence of Sphaeropsis rot in apple in Washington State. Plant Dis. 92:940-946.
9. Korf, R. P., and Zhuang, W.-Y. 1985. A synoptic key to the species of Lam bertella (Sclerotiniaceae), with comments on a version prepared for TAXADAT, Anderegg's computer program. Mycotaxon 24:361-386.

10. Lau, O. L. 1990. Fruit maturity and CA storage. Tree Fruit Postharvest J. 1:5-7.

11. Maddison, W. P., and Maddison, D. R. 2001. Mesquite: A modular system for evolutionary analysis. http://www.citeulike.org/group/894/article/ 2344980/

12. Meheriuk, M. 1993. CA storage conditions for apples, pears, and nashi. Pages 819-841 in: Proc. Sixth Int. Contr. Atm. Res. Conf. Cornell University, Ithaca, NY.

13. Moncalvo, J. M., Lutzoni, F., Rehner, S. A., Johnson, J., and Vilgalys, R. 2000. Phylogenetic relationships of agaric fungi based on nuclear large subunit ribosomal DNA sequences. Syst. Biol. 49:278-305.

14. Murakami, T., Morikawa, Y., Hashimoto, M., Okuno, T., and Harada, Y. 2004. Lambertellols A and B, Novel 3, 4-Dihydronaphthalen-1 (2 H)-ones with Spiro-butenolide Produced by Lambertella sp. 1346. Org. Lett. 6:157160.

15. Murakami, T., Sasaki, A., Fukushi, E., Kawabata, J., Hashimoto, M., and Okuno, T. 2005. Lambertellol C, a labile and novel biosynthetic congener of lambertellols A and B. Bioorg. Med. Chem. Lett. 15:2587-2590.

16. Murakami, T., Takada, N., Harada, Y., Okuno, T., and Hashimoto, M. 2007. Stimulation of the biosynthesis of the antibiotics lambertellols by the mycoparasitic fungus Lambertella corni-maris under the acidic conditions produced by its host fungus in vitro. Biosci. Biotechnol. Biochem. 71:12301235 .

17. NASS. 2012. Value of Washington's 2011 Agricultural Production Sets Record High. http://www.nass.usda.gov/Statistics_by_State/Washington/ Publications/Current_News_Release/Top40_2012.pdf

18. Nomiya, M., Murakami, T., Takada, N., Okuno, T., Harada, Y., and Hashimoto, M. 2008. Syntheses of Lambertellols and their stable analogues; Investigation of the real active species in the Mycoparasitism by Lambertella species. J. Org. Chem. 73:5039-5047.

19. Posada, D. 2008. jModelTest: Phylogenetic model averaging. Mol. Biol Evol. 25:1253-1256.

20. Rambaut, A. 2007. FigTree, a graphical viewer of phylogenetic trees. http://tree.bio.ed.ac.uk/software/figtree

21. Rosenberger, D. A. 2014. Blue mold. Pages 76-77 in: Compendium of Apple and Pear Diseases and Pests. T. B. Sutton, H. S. Aldwinckle, A. M. Agnello, and J. F. Walgenbach, eds. American Phytopathological Society, St. Paul, MN

22. Rosenberger, D. A. 2014. Postharvest diseases. Page 75 in: Compendium of Apple and Pear Diseases and Pests. T. B. Sutton, H. S. Aldwinckle, A. M. Agnello, and J. F. Walgenbach, eds. American Phytopathological Society, St. Paul, MN.

23. Spotts, R. A. 2014. Bull's-eye rot. Pages 78-79 in: Compendium of Apple and Pear Diseases and Pests. T. B. Sutton, H. S. Aldwinckle, A. M. Agnello, and J. F. Walgenbach, eds. American Phytopathological Society, St. Paul, $\mathrm{MN}$

24. Sproston, T., Jr. 1969. Antibiotic lambertellin and method for production. Pat. No. 3,438,998. http://www.archpatent.com/patents/3438998/

25. Vilgalys, R., and Hester, M. 1990. Rapid genetic identification and mapping of enzymatically amplified ribosomal DNA from several Cryptococcus species. J. Bacteriol. 172:4238-4246.

26. Von Höhnel, F. 1918. Fragmente zur Mykologie (XXI. Mitteilung, Nr. 1058 bis 1091). Sitzungsber. Kaiserl. Akad. Wiss. Math.-Naturwiss. Ci. Abt. I. 127:329-393.

27. Whetzel, H. H. 1943. A monograph of Lambertella, a genus of brownspored inoperculate Discomycetes. Lloydia 6:18-52.

28. White, T. J., Bruns, T., Lee, S., and Taylor, J. 1990. Amplification and direct sequencing of fungal ribosomal RNA genes for phylogenetics. Pages 315 322 in: PCR Protocols: A Guide to Methods and Applications. Academic Press, Orlando, FL

29. Wood, R. K. S. 1953. The antagonism of Lambertella corni-maris to fungi and bacteria. Trans. Br. Mycol. Soc. 36:109-110.

30. Xiao, C. L. 2014. Gray mold. Pages 77-78 in: Compendium of Apple and Pear Diseases and Pests. T. B. Sutton, H. S. Aldwinckle, A. M. Agnello, and J. F. Walgenbach, eds. American Phytopathological Society, St. Paul, MN.

31. Xiao, C. L., and Boal, R. J. 2004. Prevalence and incidence of Phacidiopycnis rot in d'Anjou pears in Washington State. Plant Dis. 88:413-418.

32. Xiao, C. L., and Kim, Y. K. 2010. Control of postharvest diseases in apples with reduced-risk fungicides. Stewart Postharvest Review doi:10.2212/ spr.2010.1.6 